Aelbrecht, K., Rimondini, M., Bensing, J., Moretti, F., Willems, S., Mazzi, M., Flechter, I., Deveugele, M. Quality of doctor-patient communication through the eyes of the patient: variation according to the patient's educational level. Advances in Health Sciences Educatic 2015, 20(4), 873-884

\begin{tabular}{|l|l|}
\hline $\begin{array}{l}\text { Postprint } \\
\text { Version }\end{array}$ & 1.0 \\
\hline Journal website & http://link.springer.com/article/10.1007\%2Fs10459-014-9569-6 \\
\hline Pubmed link & http://www.ncbi.nlm.nih.gov/pubmed/?term=25428194 \\
\hline DOI & $10.1007 / \mathrm{s} 10459-014-9569-6$ \\
\hline
\end{tabular}

This is a NIVEL certified Post Print, more info at http://www.nivel.eu

\title{
Quality of doctor-patient communication through the eyes of the patient: variation according to the patient's educational level
}

\author{
Karolien Aelbrecht, Michela Rimondini, Jozien Bensing, Francesca Moretti, \\ Sara Willems, Mariangela Mazzi, IAN Fletcher, Myriam DeVeugele
}

\begin{abstract}
Good doctor-patient communication may lead to better compliance, higher patient satisfaction, and finally, better health. Although the social variance in how physicians and patients communicate is clearly demonstrated, little is known about what patients with different educational attainments actually prefer in doctor-patient communication. In this study we describe patients' perspective in doctor-patient communication according to their educational level, and to what extent these perspectives lean towards the expert opinion on doctor-patient communication. In a multi-center study (Belgium, The Netherlands, UK and Italy), focus group discussions were organised using videotaped medical consultations. A mixed methods approach was used to analyse the data. Firstly, a difference in perspective in communication style was found between the lower educated participants versus the middle and higher educated participants. Secondly, lower educated participants referred positively most to aspects related to the affective/emotional area of the medical consultation, followed by the taskoriented/problem-focused area. Middle and higher educated participants positively referred most to the task-oriented/problem-focused area. The competency of the physician was an important category of communication for all participants, independent of social background. The results indicate that the preferences of lower educated participants lean more towards the expert opinion in doctor-patient communication than the middle and higher educated participants. Patients' educational level seems to influence their perspective on communication style and should be taken into account by physicians. Further quantitative research is needed to confirm these results.
\end{abstract}

\section{INTRODUCTION}

Equity in health care is a major issue in the health policy debate. The central principle of the concept is equal access, treatment, and treatment outcomes for people in equal need (Whitehead et al. 2001). It refers to the fact that personal variables (e.g. age) and social variables (e.g. income) should not dictate that people 
Aelbrecht, K., Rimondini, M., Bensing, J., Moretti, F., Willems, S., Mazzi, M., Flechter, I., Deveugele, M. Quality of doctor-patient communication through the eyes of the patient: variation according to the patient's educational level. Advances in Health Sciences Educatite 2015, 20(4), 873-884

with similar needs for health care enter through different doors (public vs. private providers), are treated differently in terms of the type or intensity of services provided, are more or less involved in treatment decisions, or receive more or less information (Aday et al. 1999). Yet, research shows that doctor-patient communication tends to differ according to the educational background of the patient. Patients with a lower educational background are significantly less involved in treatment decisions, are approached in a more directive way during the consultation, and are less frequently asked to take responsibility for care than patients with a higher education (Verlinde et al. 2012).

This social variance in doctor-patient communication seems to indicate that there is inequity in communication in health care. For example, doctors might be less informative with less educated and lower income patients, because they assume that these patients are not particularly interested in learning about their health or do not understand this information (Williams et al. 2010; Cerin and Leslie 2008; BaronEpel et al. 2007; Starfield 2006; Street 1991; Waitzkin 1985). Yet, even though physicians often ground their behaviour on these perceptions, it is not clear to what extent these perceptions are in accordance with patients' needs and preferences. Studies exploring the patient side of communication merely focus on describing patients' actual behaviour. They report that patients from lower social classes are less likely to ask questions and exhibit their opinions. They also react with less affect and take less initiative to increase their participation in the decision making process (Verlinde et al. 2012; Longtin et al. 2010; Smith et al. 2009; Bernheim et al. 2008). However, not all studies confirm these findings; a study conducted by Street did not find a relation between the frequency of the patients asking questions and his/her educational background (Street 1991). Furthermore, no studies have reported on social differences in patients' expectations regarding doctor-patient communication. More and more, medical students are receiving communication skills training throughout their medical studies. The content of the training courses, however, is usually derived from psychological theories and determined by professional experts (e.g. doctors, psychologists, and nurses) (von Fragstein et al. 2008; Kinderman and Humphris 1995), and patients are seldom involved in the development of these courses or in the development of clinical guidelines (Boivin et al. 2010). Moreover, several studies show a low correlation between patients' and professionals' quality assessments, underlining the need for a more direct approach to tapping patients' views about the quality of doctor-patient communication (Mazor et al. 2005; Greco et al. 2002; Rothman and Cusimano 2000). Therefore, a multi-center study was set up in Belgium, the Netherlands, UK, and Italy.

The objective of this study is twofold. First, to analyse whether there is a difference in the kind of topics participants address when talking about doctors' communication style according to their educational level, and to describe these differences, if any. Second, to examine which participants lean most towards an expert opinion on doctor-patient communication.

\section{METHODS}

\section{Background}

Data were derived from the GULiVER project, an international, multi-center study in Belgium (Ghent University), the Netherlands (Utrecht University), United Kingdom (University of Liverpool), and Italy (University of Verona). 
Aelbrecht, K., Rimondini, M., Bensing, J., Moretti, F., Willems, S., Mazzi, M., Flechter, I., Deveugele, M. Quality of doctor-patient communication through the eyes of the patient: variation according to the patient's educational level. Advances in Health Sciences Educatite 2015, 20(4), 873-884

A study design using focus group discussions (FGDs) was adopted. In all four countries the same procedures were followed according to a detailed protocol, pretested with three pilot panels. The detailed protocol of the GULiVER study is described in a related paper (Moretti et al. 2012).

Ethical approval to use the recordings in this study was given by the University of Liverpool.

\section{Recruitment of participants}

To recruit the participants, the research teams applied stratified sampling according to age $(18-30 ; 31-49 ; \geq 50)$ and gender (separate male and female panels). Inclusion criteria were (a) age over 18 years; (b) at least one GP-visit over the last 12 months; (c) speaking one of the country's official languages; and (d) not being involved in a medical lawsuit or formal complaint with a care provider during the last 2 years. The participants were approached in a context not related to any medical consultation (e.g. in shopping malls, railway stations, and market places).

\section{Measurement instruments and data collection procedure}

To collect the data, thirty-five data collection sessions were organised: nine in Italy, the Netherlands, and United Kingdom, and eight in Belgium. In each session 6-9 participants were included. During these sessions (all lasting around $6 \mathrm{~h}$ ) different data collection methods were used. The resulting heterogeneity in the data was intended to generate a comprehensive view of the participants' perspectives. Firstly, the participants filled out a questionnaire on socio-demographic characteristics including age, gender, and educational level. The latter was based on the highest educational attainment of the participant and was categorised in three categories: low (no education or primary school), middle (secondary school), and high (higher education) educational level.

Then, video-recorded medical consultations were presented. Two sets of four standardised recordings were used: one set on vaginal discharge after unprotected sex and one set on severe menstrual pain. Both scenarios referred to clinical problems that can be associated with high levels of emotional distress. These recordings were made as part of the summative fourth year OSCE's (Objective Structured Clinical Examination; i.e. medical consultation with a simulated patient) at the Liverpool Medical School to assess the competency of the medical students' communication skills in a primary health care setting. Four video recordings were selected per scenario: one with high ratings from both examiner (E) and simulated patient (SP), one with a high rate from the examiner and a low rate from the simulated patient, one with a low rate from the examiner and a high rate from the simulated patient, and one with a low rate from both the examiner and the simulated patient. The recordings were dubbed (Italy) or subtitled (Belgium and the Netherlands). After watching the recordings, each participant was asked to rank them from 1 to 4 : " 1 " being the recording of the consultation done by their most preferred doctor to " 4 " being the recording of the consultation performed by their least preferred doctor.

Next, the participants participated in a focus group discussion. Participants were invited to share their views on the doctors' performance, and the underlying reasons for their choices were explored. Because they were not directly involved in the consultations, the participants could freely judge and comment on the student doctors' communicative performance, while still representing a patient perspective. 
Aelbrecht, K., Rimondini, M., Bensing, J., Moretti, F., Willems, S., Mazzi, M., Flechter, I., Deveugele, M. Quality of doctor-patient communication through the eyes of the patient: variation according to the patient's educational level. Advances in Health Sciences Educatic 2015, 20(4), 873-884

After an hour, the discussion - if it had not already ended - was summarised and closed.

All focus group discussions were moderated by a native speaker trained in the method of focus group discussions. The discussions were audiotaped and fully transcribed verbatim, including information on the identity of the participant speaking. In order to make the transcripts accessible to researchers in all four countries, they were translated into English. Because of privacy issues all references to names (e.g. the participants' name, names of children, and doctors) were replaced by anonymous numbers.

\section{Data coding}

The four research teams coded one or two transcripts independently. To do so, the principles of the framework approach, in which the pre-defined questions and objectives are used as boundaries for the coding, were applied (Mazzi et al. 2013; Moretti et al. 2011). Subsequently, codes were compared and differences in coding were discussed in order to develop a common understanding of all codes. This classification system was then used to code the transcripts of all the remaining focus group discussions.

The applied coding scheme was divided into six areas of communication of which three will be discussed in this article - i.e. process-oriented area (i.e. all the comments about the way a doctor is handling the process of the conversation), taskoriented/problem-focused area (i.e. all the comments about the overall attitude of the doctor regarding the instrumental tasks during the conversation) and affective/emotional area (i.e. all the comments about the overall attitude of the doctor regarding the affective/emotional components)—, 12 main categories, and 41 subcategories (Moretti et al. 2011). For more detailed information about the scheme see Table 1 of Appendix.

\section{Statistical analyses}

A total of 7,067 quotes were coded, but 1,598 quotes were excluded from the analyses because these were not related to the topic of the study (i.e. small talk, e.g. someone asking for more coffee). The codes were inserted in the statistical software program SPSS (version 20.0.0, IBM) and linked with the information of the participant who was talking.

First, the number of utterances according one's educational level was calculated and tested using one-way ANOVA. Further, to answer the first research question, a Chi squared test of independence with adjusted residual analysis was used (Agresti 2002). For the second research question, the videotaped consultations with a high expert assessment (i.e. high E-high SP and high E-low SP) were merged and a generalised estimating equation approach was used to provide a practical method with good statistical properties to model data that exhibit association, but cannot be modelled as multivariate normal (Johnston and Stokes 1999).

\section{RESULTS}

\section{Participant characteristics}

A total of 259 lay people participated in the GULiVER study. UK data were excluded for this article because reliable information on the educational level of the participants was missing. As a result, for this paper, the data of 178 participants were analysed: 59 participants in the Netherlands, 71 in Italy, and 48 in Belgium. 
Aelbrecht, K., Rimondini, M., Bensing, J., Moretti, F., Willems, S., Mazzi, M., Flechter, I., Deveugele, M. Quality of doctor-patient communication through the eyes of the patient: variation according to the patient's educational level. Advances in Health Sciences Education: 2015, 20(4), 873-884

The sample included 79 male and 99 female participants, all between 18 and 71 years old. There were 31 participants with a lower educational level, 73 participants with a middle, and 74 participants with a higher educational level included (see Table 2 of Appendix).

\section{Discussed topics by educational level}

Lower educated participants talked significantly less during the focus group discussions than middle and higher educated participants: a mean of 15 quotes per lower educated participant, a mean of 17 quotes per middle educated and a mean of 20 quotes per higher educated participants. Consequently, lower educated participants were talking for $14 \%$ of the duration of the discussion, middle educated participants for $40 \%$ of the duration, and higher educated participants for $46 \%$ of the duration. This was found statistically significant as determined by one-way ANOVA $(F(2,3165)=12.233, p=0.000)$.

When asking participants about their perspective in doctor-patient communication ("Why do you prefer this doctor?"), lower educated participants mostly referred to the affective/emotional area of communication ( $41.1 \%$ of the quotes expressed by this group; $187 / 454$ quotes), followed by the task-oriented/problem-focused area of communication $(40.9 \% ; 186 / 454)$. Only $17.8 \%$ of the quotes $(81 / 454)$ referred to the process-oriented area of communication. For the middle and the higher educated participants, the task-oriented area was most frequently referred to (middle: $40.9 \%$; 515/1,259; high: $41.8 \% ; 609 / 1,455)$. The affective/emotional area came second (middle: $35.1 \%$; 443/1,259; high: $30.9 \%$; 450/1,455), and this group referred to the process-oriented area the least (middle: $23.9 \% ; 301 / 1,259$; high: $27.2 \% ; 396 / 1,455$ ). This was found statistically significant for the task-oriented/problem-focused area and the affective/emotional area as determined by Pearson's Chi square test, respectively $\chi^{2}(6)=14.9786, p=0.020$ and $\chi^{2}(14)=84.8600, p=0.000$.

When looking within the areas, we found an effect of the patient's educational level in four categories. Within the process-oriented area, the category "structuring" was statistically significant, with $\chi^{2}(6)=39.9304, p=0.000$, while in the taskoriented/problem-focused area, the categories "attitude of the doctor" and "collecting information" were statistically significant, with $\chi^{2}(10)=19.9900, p=0.029$ and $\chi^{2}$ $(6)=14.7640, p=0.022$, respectively. Finally, within the affective/emotional area, the category "attitude of the doctor" was statistically significant, with $\chi^{2}$ $(14)=84.8600, p=0.000$. Higher educated participants referred significantly more to these four categories.

When looking within these four significant categories, we found differences between the subcategories. Within the category "structuring", lower educated participants refer more to "time issues" than middle and higher educated participants, while middle educated participants refer more to "opening or closing of the interview". Within the category "attitude of the doctor" in the task-oriented/problem-focused area, lower educated participants refer more to the subcategories "business-like/to the point", "other/general", and "competency (of the doctor)" than middle and higher educated participants. The subcategory "self-confident" is often referred to by the middle educated participants. Within the category "collecting information", lower educated participants refer more to the subcategories "medical" and "biopsychosocial" than middle and higher educated participants. Within the category "attitude of the doctor" in the affective/emotional area, lower educated participants refer more to the subcategories "inviting attitude (of the doctor)", "showing interest 
Aelbrecht, K., Rimondini, M., Bensing, J., Moretti, F., Willems, S., Mazzi, M., Flechter, I., Deveugele, M. Quality of doctor-patient communication through the eyes of the patient:
variation according to the patient's educational level. Advances in Health Sciences Education: 2015, 20(4), 873-884

in the patient/commitment", "facilitating" and "listening" than middle and higher educated participants. Both lower and middle educated participants refer significantly more to "pleasant attitude (of the doctor)" than higher educated participants. The subcategories "empathic (attitude of the doctor)" and "reassurance/trust (in the doctor)" were often referred to by the middle educated participants.

\section{The expert opinion versus layman's opinion on good doctor-patient communication}

Participants with a lower educational level preferred the doctors who received a high score by the experts (i.e. examiner/expert), significantly more than the middle and higher educated participants. The odds of choosing the expert opinion on good doctor-patient communication is 1.443 times higher for participants with a lower educational level than for participants with a secondary diploma (95\% CI 1.0302.021).

No significant effect was found for the higher educated participants, meaning they do not have a specific preference.

\section{DisCUSSION}

This study shows that lower educated participants expressed their perspectives during the focus group discussions significantly less than middle and higher educated participants. Moreover, participants' perspective on doctor-patient communication differ according to the participant's educational level. Lower educated participants emphasised the emotional and task-oriented/problem-focused area more, while for the middle and higher educated people the emotional area came second, after the task-oriented/problem-focused area. For all participants, the process-oriented area was least referred to. The differences in participants' education were found statistically significant. Furthermore, we saw that participants with a lower educational level preferred the expert opinion on doctor-patient communication significantly more than the middle and higher educated participants.

First, we found that lower educated participants talked less during the focus group discussions. Willems et al. (2004) described how these patients often find themselves in a vicious circle, where their more passive behaviour in a consultation elicits a lessinvolved behaviour from the doctor. This is not a new result. Lower participation from lower educated people was also found in other studies (Galea and Tracy 2007; Moorman et al. 1999). It means that the voices of lower educated people are less heard in focus group studies. However, focus groups discussions are meant to be used to encourage participants to explore specific issues and attitudes. As stated by Kitzinger in 1994: "Tapping into such interpersonal communication is also important because this can highlight (sub)cultural values or group norms. It also makes them useful in studies examining why different sections of the population make differential use of health services." Our finding that participants with low educational levels are less talkative in focus group discussions means that in studies which are seeking for differential opinions and experiences, special effort is needed to give these people a voice, either by organising homogeneous groups of people with the same educational levels, or by targeted invitations by the moderator in heterogeneous focus groups.

Lower educated participants seem to attach the most importance to the subcategories "inviting attitude (of the doctor)", "pleasant attitude (of the doctor)", "showing 
Aelbrecht, K., Rimondini, M., Bensing, J., Moretti, F., Willems, S., Mazzi, M., Flechter, I., Deveugele, M. Quality of doctor-patient communication through the eyes of the patient: variation according to the patient's educational level. Advances in Health Sciences Educate 2015, 20(4), 873-884

interest in the patient/commitment", "facilitating", "listening", "(being) businesslike/to the point", "competency (of the doctor)", "collecting medical and biopsychosocial information (by the doctor)", and "time issues". Participants with a lower educational level also lean more towards the expert opinion on doctor-patient communication than the middle and higher educated participants. This is in accordance with the general educational guidelines of what is generally considered as good doctor-patient communication: doctors need to be competent, have to know their job, while adopting a patient-centered style (Roter and Hall 2006). At the same time, this result contrasts with what physicians tend to do, namely using a more dominant communication style when dealing with patients from lower educational backgrounds (Verlinde et al. 2012; Smith et al. 2009; Kelly-Irving et al. 2009). This means that doctors often adapt their communication style based only on ingrained prejudices, and therefore, in the opposite direction.

Moreover, while the lower educated participants described the affective/emotional area and the invitation of the doctor to participate in the consultation as most important, the middle and higher educated participants indicated the taskoriented/problem-focused area as most important. Looking in particular to the middle educated participants, we saw that they attach the most importance to the subcategories "opening or closing of the interview", "self-confident (attitude of the doctor)", "pleasant attitude (of the doctor)", "empathic (attitude of the doctor)" and "reassurance/trust (in the doctor)". A possible explanation could be that the field of affective communication is perhaps the field where lower educated people feel competent enough to make comments, and feel less secure when more medical issues arise. Also, people with a higher educational background are perhaps more aware of the ways in which doctors give direction to a consultation and have more to say about this.

It appears that the specific needs of the lower, middle, and higher educated participants in a medical consultation occur on different levels. While lower educated participants explicitly ask to be invited to take part in a consultation, other elements of a consultation, in particular about the attitude of the doctor towards the patient, seem to be more important for middle educated participants. It is possible that the middle educated are asked to take part in the consultation, and as a result attach more importance to other elements that are perhaps missing for them in a consultation. None of the subcategories stood out for the higher educated participants, probably because their expectations were met (Fiscella et al. 2002).

Looking at the concept of shared decision making, McKinstry (2000) found that a lower educational level was associated with a lower preference for the shared approach. However, it was not found to be an independent predictor and, moreover, specific minorities within each group had opposite views than the rest. And yet, this is what we often see in practice, where some physicians assume that they know the patient's preference, and act on this without first explicitly testing this assumption. Moreover, both patient and physician have to be willing to share the process. And as described by Charles et al. (1997), "It takes at least two to tango" for shared decision making to occur in a medical consultation.

This study has important strengths and limitations. The GULiVER study is one of the few to research the perspectives of lay people regarding doctor-patient communication. The importance of this type of research was strengthened by Frenk et al. (2010): "Health is about people; thus the core driving purpose of professional 
Aelbrecht, K., Rimondini, M., Bensing, J., Moretti, F., Willems, S., Mazzi, M., Flechter, I., Deveugele, M. Quality of doctor-patient communication through the eyes of the patient: variation according to the patient's educational level. Advances in Health Sciences Educate 2015, 20(4), 873-884

education must be to enhance the performance of health systems for meeting the needs of patients and populations in an equitable and efficient manner." Furthermore, it is done on a large scale, in four different countries, applying a strict and well thought out method to ensure the validity of the results as much as possible. Because of the explicit use of group interaction, focus group discussion is a widely used technique to explore people's experiences and perspectives (Kitzinger 1994). The use of the OSCE's to record the recordings can be criticised since recordings from this setting do not necessarily resemble the natural variance observed in everyday medical practices. However, for the aim of this study, namely to compare lay people's opinions, we needed to show all participants the same set of (standardised) recordings, and this could easily be achieved by using the OSCE stations (Moretti et al. 2012). Also, the use of only gynaecological scenarios might have been a bias in this study. These specific scenarios containing levels of emotional distress were used in order to be able to assess the medical students' communication skills. Furthermore, in selecting the participants, we stratified on age and gender, but not on education. While aiming for homogeneity is usually recommended for each group, bringing together a diverse group can maximise exploration of different perspectives within a group setting (Kitzinger 1994). Taking this advantage and the research aim into account, we mixed the focus groups in terms of educational background of the participants. Nevertheless, the results concerning lower educated participants being less expressive can call this decision into question. Finally, another important limitation for this study is the limited number of included participants; this was due to the exclusion of the British data.

\section{CONCLUSION}

Patients' educational level seems to influence their perspective on communication style. Patients from different educational backgrounds have different needs in consultations, in particular with regard to doctor-patient communication. However, instead of behaving like most patients want, doctors must be aware of these specific differences in needs, and take them into account during consultations. Further quantitative research is needed to confirm these results.

\section{ACKNOWLEDGMENTS}

We would like to thank all the participants for their significant contribution to the study. Also, we would like to thank the other members of the GULiVER study, as well as the moderators of the focus groups for their committed participation in the study.

\section{REFERENCES}

Aday, L. A., Begley, C. E., Lairson, D. R., Slater, C. H., Richard, A. J., \& Montoya, I. D. (1999). A framework for assessing the effectiveness, efficiency, and equity of behavioral healthcare. The American Journal of Managed Care, 5, SP25-SP44.

Agresti, A. (2002). Categorical data analysis (2nd ed.). New Jersey: Wiley.CrossRef Baron-Epel, O., Garty, N., \& Green, M. S. (2007). Inequalities in use of health services among Jews and Arabs in Israel. Health Services Research, 42, 1008-1019.CrossRef

Bernheim, S. M., Ross, J. S., Krumholz, H. M., \& Bradley, E. H. (2008). Influence of patients' socioeconomic status on clinical management decisions: A qualitative study. The Annals of Family Medicine, 6, 53-59.CrossRef 
Aelbrecht, K., Rimondini, M., Bensing, J., Moretti, F., Willems, S., Mazzi, M., Flechter, I., Deveugele, M. Quality of doctor-patient communication through the eyes of the patient: variation according to the patient's educational level. Advances in Health Sciences Educate 2015, 20(4), 873-884

Boivin, A., Currie, K., Fervers, B., Gracia, J., James, M., Marshall, C., et al. (2010). Patient and public involvement in clinical guidelines: International experiences and future perspectives. Quality \& Safety in Health Care, 19(5), 1-4.

Cerin, E., \& Leslie, E. (2008). How socio-economic status contributes to participation in leisure-time physical activity. Social Sciences and Medicine, 66, 2596-2609.CrossRef

Charles, C., Gafni, A., \& Whelan, T. (1997). Shared decision-making in the medical encounter: What does it mean? (or it takes at least two to tango). Social Sciences and Medicine, 44(5), 681-692.CrossRef

Fiscella, K., Goodwin, M. A., \& Stange, K. C. (2002). Does patient educational level affect office visits to family physicians? Journal of the National Medical Association, 94(5), 157165.

Frenk, J., Chen, L., Bhutta, Z., Cohen, J., Crisp, N., Evans, T., et al. (2010). Health professionals for a new century: Transforming education to strengthen health systems in an interdependent world. The Lancet, 376(9756), 1923-1958.CrossRef

Galea, S., \& Tracy, M. (2007). Participation rates in epidemiologic studies. Annals of Epidemiology, 17, 643-653.CrossRef

Greco, M., Spike, N., Powell, R., \& Brownlea, A. (2002). Assessing communication skills of GP registrars: A comparison of patient and GP examiner ratings. Medical Education, 36(4), 366-376. CrossRef

Johnston, G., \& Stokes, M. (1999). Repeated measures analysis with discrete data using the SAS system. Cary, NC: SAS Institute Inc.

Kelly-Irving, M., Rolland, C., Afrite, A., Cases, C., Dourgnon, P., Lombrail, P., et al. (2009). Patient-physician interaction in general practice and health inequalities in a multidisciplinary study: design, methods and feasibility in the French intermede study. BMC Health Services Research, 9, 66.CrossRef

Kinderman, P., \& Humphris, G. (1995). Clinical communication skills teaching: The role of cognitive schemata. Medical Education, 29(6), 436-442.CrossRef

Kitzinger, J. (1994). The methodology of Focus Groups: The importance of interaction between research participants. Sociology of Health and IIIness, 16(1), 103-121.CrossRef

Longtin, Y., Sax, H., Leape, L. L., Sheridan, S. E., Donaldson, L., \& Pittet, D. (2010). Patient participation: current knowledge and applicability to patient safety. Mayo Clinic Proceedings, 85, 53-62.CrossRef

Mazor, K., Ockene, J. K., Rogers, J., Carlin, M. M., \& Quirk, M. E. (2005). The relationship between checklist scores on a communication OSCE and analogue patients' perceptions of communication. Advances in Health Sciences Education, 10(1), 37-51.CrossRef

Mazzi, M. A., Rimondini, M., Deveugele, M., Zimmermann, C., Moretti, F., van Vliet, L., Deledda, G., Fletcher, I., \& Bensing, J. (2013). What do people appreciate in physicians' communication An international study with focus groups using videotaped medical consultations. Health Expectations. http://www.ncbi.nlm.nih.gov/pubmed/23796047

McKinstry, B. (2000). Do patients wish to be involved in decision making in the consultation? A cross-sectional survey with video vignettes. BMJ, 321, 867-871.CrossRef

Moorman, P., Newman, B., Millikan, R. C., Tse, C.-K. J., \& Sandler, D. P. (1999).

Participation rates in a case-control study: The impact of age, race, and race of interviewer. Annals of Epidemiology, 9, 188-195.CrossRef

Moretti, F., Fletcher, I., Mazzi, M., Deveugele, M., Rimondini, M., Geurts, C., et al. (2012). GULiVER: travelling into the heart of good doctor-patient communication from a patient perspective. A multicentre study. European Journal of Public Health, 22(4), 464469. CrossRef

Moretti, F., Vliet, L., Bensing, J., Deledda, G., Mazzi, M., Rimondini, M., et al. (2011). A standardized approach to qualitative content analysis of focus group discussions from different countries. Patient Education and Counseling, 82(3), 420-428.CrossRef

Roter, D., \& Hall, J. A. (2006). Doctors talking with patients/patients talking with doctors: Improving communication in medical visits. Westport, Conn: Praeger.

Rothman, A. I., \& Cusimano, M. (2000). A comparison of physician examiners', standardized patients', and communication experts' ratings of international medical graduates' English proficiency. Academic Medicine, 75(12), 1206-1211.CrossRef 
Aelbrecht, K., Rimondini, M., Bensing, J., Moretti, F., Willems, S., Mazzi, M., Flechter, I., Deveugele, M. Quality of doctor-patient communication through the eyes of the patient: variation according to the patient's educational level. Advances in Health Sciences Education: 2015, 20(4), 873-884

Smith, S. K., Dixon, A., Trevena, L., Nutbeam, D., \& McCaffery, K. J. (2009). Exploring patient involvement in healthcare decision making across different education and functional health literacy groups. Social Science and Medicine, 69, 1805-1812.CrossRef

Starfield, B. (2006). State of the art in research on equity in health. Journal of Health Politics, Policy and Law, 31, 11-32.CrossRef

Street, R. (1991). Information giving in medical consultations: The influence of patients' communicative styles and personal characteristics. Social Science and Medicine, 32, $541-$ 548.CrossRef

Verlinde, E., De Leander, N., De Maesschalck, S., Deveugele, M., \& Willems, S. (2012). The social gradient in doctor-patient communication. International Journal for Equity in Health, 11(12), 1-14.

von Fragstein, M., Silverman, J., Cushing, A., Quilligan, S., Salisbury, H., \& Wiskin, C. (2008). UK consensus statement on the content of communication curricula in undergraduate medical education. Medical Education, 42(11), 1100-1107.CrossRef

Waitzkin, H. (1985). Information giving in medical care. Journal of Health and Social Behavior, 26, 81-101.CrossRef

Whitehead, M., Dahlgren, G., \& Evans, T. (2001). Equity and health sector reforms: Can lowincome countries escape the medical poverty trap? Lancet, 358(9284), 833-836.CrossRef

Willems, S., De Maesschalck, S., Deveugele, M., Derese, A., \& De Maeseneer, J. (2004). Socio-economic status of the patient and doctor-patient communication: Does it make a difference? Patient Education and Counseling, 56(2005), 139-146.

Williams, D. R., Mohammed, S. A., Leavell, J., \& Collins, C. (2010). Race, socioeconomic status, and health: Complexities, ongoing challenges, and research opportunities. Annals of the New York Academy of Sciences: The Biology of Disadvantage, 1186, 69-101.

\section{APPENDIX}

Table 1 Number of times participants referred to each of the categories and subcategories in doctor-patient communication (according to educational level)

\begin{tabular}{|c|c|c|c|c|c|}
\hline \multirow{2}{*}{$\begin{array}{l}\text { Area of } \\
\text { communication }\end{array}$} & \multirow[t]{2}{*}{ Category } & \multirow[t]{2}{*}{ Subcategory } & \multicolumn{3}{|c|}{$\begin{array}{l}\text { Educational level (no. of } \\
\text { quotes) }\end{array}$} \\
\hline & & & Low & Middle & High \\
\hline \multirow[t]{9}{*}{$\begin{array}{l}\text { Process-oriented } \\
\text { area } \mathrm{a}(\mathrm{n}=778)\end{array}$} & $\begin{array}{l}\text { Structuring } \\
(\mathrm{n}=394)\end{array}$ & $\begin{array}{l}\text { Changing of topics } \\
\text { and signposting }\end{array}$ & 2 & 23 & 51 \\
\hline & & Flexibility & 13 & 49 & 108 \\
\hline & & Time issues & 16 & 33 & 26 \\
\hline & & $\begin{array}{l}\text { Opening or closing } \\
\text { of the interview }\end{array}$ & 6 & 39 & 28 \\
\hline & $\begin{array}{l}\text { Summarising } \\
(\mathrm{n}=105)\end{array}$ & Summarising & 10 & 50 & 45 \\
\hline & $\begin{array}{l}\text { Patient- } \\
\text { involving } \\
(\mathrm{n}=131)\end{array}$ & Sharing plans/ideas & 8 & 21 & 23 \\
\hline & & Asking permission & 3 & 10 & 28 \\
\hline & & Verifying & 2 & 14 & 22 \\
\hline & $\begin{array}{l}\text { Speaking } \\
\text { peculiarities } \\
(\mathrm{n}=148)\end{array}$ & Repetition & 9 & 24 & 21 \\
\hline
\end{tabular}


Aelbrecht, K., Rimondini, M., Bensing, J., Moretti, F., Willems, S., Mazzi, M., Flechter, I., Deveugele, M. Quality of doctor-patient communication through the eyes of the patient: variation according to the patient's educational level. Advances in Health Sciences Education: 2015, 20(4), 873-884

\begin{tabular}{|c|c|c|c|c|c|}
\hline \multirow{4}{*}{$\begin{array}{l}\text { Area of } \\
\text { communication }\end{array}$} & \multirow[t]{2}{*}{ Category } & \multirow[t]{2}{*}{ Subcategory } & \multicolumn{3}{|c|}{$\begin{array}{l}\text { Educational level (no. of } \\
\text { quotes) }\end{array}$} \\
\hline & & & Low & Middle & High \\
\hline & & Fillers & 5 & 26 & 23 \\
\hline & & Comprehensibility & 7 & 12 & 21 \\
\hline \multirow[t]{15}{*}{$\begin{array}{l}\text { Task- } \\
\text { oriented/problem- } \\
\text { focused area b } \\
(\mathrm{n}=1,310)\end{array}$} & $\begin{array}{l}\text { Attitude of } \\
\text { the doctor } \\
(\mathrm{n}=790)\end{array}$ & Self-confident & 12 & 52 & 58 \\
\hline & & Complete picture & 21 & 58 & 86 \\
\hline & & $\begin{array}{l}\text { Business-like/To the } \\
\text { point }\end{array}$ & 17 & 30 & 53 \\
\hline & & Other/General & 7 & 23 & 11 \\
\hline & & Clarity of interview & 3 & 20 & 32 \\
\hline & & Competency & 51 & 118 & 138 \\
\hline & $\begin{array}{l}\text { Collecting } \\
\text { information } \\
(\mathrm{n}=252)\end{array}$ & Medical & 18 & 32 & 30 \\
\hline & & Bio-psychosocial & 14 & 30 & 28 \\
\hline & & Psychological & 2 & 13 & 7 \\
\hline & & Social & 5 & 29 & 44 \\
\hline & $\begin{array}{l}\text { Giving } \\
\text { information } \\
(\mathrm{n}=169)\end{array}$ & Medical & 11 & 40 & 60 \\
\hline & & Bio-psychosocial & 6 & 17 & 26 \\
\hline & & Psychological & 1 & 1 & 0 \\
\hline & & Social & 0 & 2 & 5 \\
\hline & $\begin{array}{l}\text { Providing } \\
\text { Solution } \\
(\mathrm{n}=99)\end{array}$ & Providing solutions & 18 & 50 & 31 \\
\hline \multirow[t]{8}{*}{$\begin{array}{l}\text { Affective/emotional } \\
\text { area } \mathrm{c}(\mathrm{n}=1,080)\end{array}$} & $\begin{array}{l}\text { Attitude of } \\
\text { the Doctor } \\
(\mathrm{n}=1,080)\end{array}$ & Inviting attitude & 22 & 42 & 45 \\
\hline & & Pleasant attitude & 22 & 51 & 44 \\
\hline & & $\begin{array}{l}\text { Showing interest in } \\
\text { patient/Commitment }\end{array}$ & 53 & 75 & 101 \\
\hline & & Empathic & 3 & 40 & 21 \\
\hline & & Facilitating & 20 & 36 & 46 \\
\hline & & Reassurance/Trust & 23 & 112 & 109 \\
\hline & & $\begin{array}{l}\text { Neutral/No personal } \\
\text { remark }\end{array}$ & 8 & 45 & 66 \\
\hline & & Listening & 36 & 42 & 18 \\
\hline
\end{tabular}

The numbers highlighted in bold represent the top 5 of communication subcategories most referred by educational level 
Aelbrecht, K., Rimondini, M., Bensing, J., Moretti, F., Willems, S., Mazzi, M., Flechter, I., Deveugele, M. Quality of doctor-patient communication through the eyes of the patient: variation according to the patient's educational level. Advances in Health Sciences Education: 7 2015, 20(4), 873-884

${ }^{a}$ For example, within the category structuring, a quote of time issues was: "Yes, it is strange that he (i.e. the doctor) was so fast, I had a feeling like, now you are filling your time... (female, The Netherlands)."

${ }^{b}$ For example, within the category attitude of the doctor, a quote of competency was: "She looked professional because of her expressions, because she did not keep on saying 'ok, all right; ok, all right' (male, Italy)."

${ }^{c}$ For example, within the category attitude of the doctor, a quote of inviting attitude was: "They (i.e. the doctors) are behind a large desk and then you are sitting at such a distance (male, Belgium)."

\section{Table 2 Sample characteristics}

\begin{tabular}{c|l|l|l|l|l}
\multicolumn{2}{l|}{} & \multicolumn{2}{l|}{ Sex } & \multicolumn{3}{|l|}{ Educational level } \\
\cline { 2 - 6 } & Male & Female & Low & Middle & High \\
\hline NL & 26 & 33 & 10 & 28 & 21 \\
\hline IT & 32 & 39 & 15 & 30 & 26 \\
\hline BE & 21 & 27 & 6 & 15 & 27
\end{tabular}

